\title{
Late Plasma Cell Depletion After Thymoglobulin Induction in Kidney Transplant Recipients
}

\author{
Juan Irure,,$^{1^{*}}$ Cristina Sango,,$^{2^{*}}$ David San Segundo, ${ }^{1}$ Gema Fernández-Fresnedo, ${ }^{2}$ \\ Juan Carlos Ruiz, ${ }^{2}$ Adalberto Benito-Hernández, ${ }^{2}$ Esther Asensio, ${ }^{1}$ \\ Marcos López-Hoyos, ${ }^{1 \neq}$ Emilio Rodrigo ${ }^{2 \neq}$
}

\begin{abstract}
Objectives: Induction therapy with rabbit antithymocyte globulin is frequently used in kidney transplant recipients and contributes to regulating the humoral alloantibody response. However, the effect of rabbit antithymocyte globulin on B-cell subpopulations, including plasma cells, has not been previously studied in humans in vivo.

Materials and Methods: We prospectively studied a cohort of 39 adult kidney transplant recipients. Twenty patients received rabbit antithymocyte globulin as induction therapy. Peripheral blood samples were obtained pretransplant and at 6 and 12 months posttransplant. $T$ and $B$ cells were acquired by flow cytometry.

Results: Total lymphocytes and CD3 and CD4 cells significantly decreased at 6 and 12 months only in patients who received rabbit antithymocyte globulin. In contrast, the CD19 population did not change after rabbit antithymocyte globulin induction. One-year circulating plasma cells remained significantly lower than pretransplant levels in patients who received rabbit antithymocyte globulin. We observed significant differences in plasma cell numbers at 12 months after transplant between patients who received rabbit antithymocyte globulin and those patients who did not receive it (median of 5 and interquartile range of 3-17 vs median of 25 and interquartile range of 12-35; $P=.001)$.
\end{abstract}

From the ${ }^{1}$ Immunology Service, and the ${ }^{2}$ Nephrology Service, University Hospital Marqués de Valdecilla-IDIVAL, University of Cantabria, Santander, Spain

Acknowledgements: This work was partially supported by grants for Fondo de Investigaciones Sanitarias-ISCIII (PI1100990, PI1400378, PI1601585, and RD16/0009/0027) and IDIVAL. The authors have no conflicts of interest to declare. We are grateful to Sandra Raso and Consuelo Agüero for their excellent technical helpful. The authors are indebted to Robbie Vincent for his linguistic assistance.

"Juan Irure and Cristina Sango contributed equally to this work.

${ }^{\ddagger}$ Marcos López-Hoyos and Emilio Rodrigo shared senior authorship for this work.

Corresponding author: Emilio Rodrigo, Nephrology Service, University Hospital "Marqués

de Valdecilla", University of Cantabria, Avda. Valdecilla sn. 39008, Santander, Spain

Phone: +34942202738Ｅ-mail: nefrce@humv.es

Experimental and Clinical Transplantation (2019)
Conclusions: Rabbit antithymocyte globulin induction leads to a late reduction in the number of circulating plasma cells at 1 year after kidney transplant. This effect can contribute to down-regulation of the humoral alloantibody response.

Key words: Induction, Lymphocyte subpopulation, Renal transplantation

\section{Introduction}

Induction therapy with an interleukin 2 receptor antagonist or a lymphocyte-depleting agent has been strongly recommended as part of the initial immunosuppressive regimen in kidney transplantation to modulate or deplete T-cell responses while alloantigen presentation occurs. ${ }^{1,2}$ Induction drugs contribute to reducing acute rejection rate and to improving graft survival compared with placebo or no induction, especially in high-risk patients. ${ }^{3-5}$ Among lymphocytedepleting agents, rabbit antithymocyte globulin (rATG) is the most frequently used induction drug in the United States and the second most frequently used in Europe and Australia/New Zealand. ${ }^{6-9}$ Differences in prescription rates among different countries and centers point to no definite indications for selecting rATG instead of other induction agents in a specific transplant recipient. However, common consensus and guidelines suggest using rATG at least in patients with a higher risk of rejection and/or delayed graft function. ${ }^{1,8,10}$

In the past decade, the humoral alloimmune response against the graft has regained importance. On the one hand, the significant role of donor-specific antibodies has been recognized in the development of antibody-mediated rejection (AbMR) that drives further kidney graft loss. ${ }^{11,12}$ On the other hand, several studies have demonstrated a specific B-cell subpopulation signature in tolerant patients. ${ }^{13-17}$ In relation to both aspects, we suspected that rATG 
could influence the humoral side of the alloimmune response. First, rATG is used to prevent and treat $\mathrm{AbMR}$ and contributes to reducing donor-specific antibodies and HLA antibodies in kidney and heart transplant recipients. ${ }^{10,18-21}$ Second, rATG has become a cornerstone agent to promote tolerance in both animal models ${ }^{22-24}$ and humans. ${ }^{25-27}$ Although it is well known that T-cell depletion constitutes the main mechanism of action of rATG, it also interacts with different immune and nonimmune cell types, such as B cells, natural killer cells, and endothelial cells. ${ }^{28,29}$ Thus, rATG triggers complement-independent apoptosis of naive, activated, and plasma B cells in vitro. ${ }^{30}$ However, the effect of rATG on B-cell subpopulations, including plasma cells, has not been previously studied in humans in vivo. ${ }^{31}$ Our aim was to analyze changes in B-cell subpopulations in kidney transplant recipients treated with rATG as induction therapy.

\section{Materials and Methods}

A cohort of 39 consecutive adult kidney transplant recipients, with procedures performed at the Marqués de Valdecilla University Hospital from February 2015 to January 2016, was prospectively studied during the first 12 months after transplant. Four patients were excluded due to pretransplant use of rituximab or because they received rATG (Thymoglobulin; Genzyme Corporation, Cambridge, MA, USA) to treat acute rejection. Standard initial immunosuppression consisted of tacrolimus, mycophenolate mofetil, and prednisone. Twenty patients received rATG as induction therapy due to simultaneous pancreas-kidney transplant $(\mathrm{n}=3)$, donation after cardiac death $(\mathrm{n}=11)$, high risk of delayed graft function $(\mathrm{n}=19)$, and/or hypersensitization $(n=5)$. Five patients received induction therapy with basiliximab. Relevant information about recipient, donor, and transplant characteristics was extracted from the prospectively maintained database of renal transplant patients at our center. One-year estimated glomerular filtration rate (eGFR) was calculated using the CKD-EPI equation. Diagnosis of acute rejection was proven with biopsy. This study was conducted according to the guidelines of the Declaration of Helsinki and was approved by the ethics committee of our hospital. All patients included in the study gave written informed consent.
Peripheral blood samples in EDTA containers were obtained pretransplant and at months 6 and 12 after transplant. Flow cytometry was performed according to standard protocol by using CytoFLEX (Beckman Coulter, Fullerton, CA, USA). Blood cells were freshly stained with the following monoclonal antibodies: CD27-FITC clone M-T271, CD138-FITC clone MI15, CD24-PE clone ML5, CD268-PE clone 7H22-E16, and immunoglobulin M-APC clone G20-127 (from BD Biosciences, San Jose, CA, USA); CD19-PC5.5 clone J3-119 (from Beckman Coulter); CD38-PC7 clone HIT2, CD5-APC clone UCHT2, CD10-APC Cy7 clone HI10a, CD25-Pacific Blue clone BC96, and IgD-Brilliant Violet 510 clone IA6-2 (from BioLegend, San Diego, CA, USA); and CD27-APC Cy7 clone M-T271, CD21-VioBlue clone HB5, and CD20-VioGreen clone REA780 (from Miltenyi, Bergisch Gladbach, Germany). These were used to identify different B-cell subsets.

Naïve B cells were defined as CD19+IgD+CD27(CD19-positive, immunoglobulin D positive, CD27 negative), different subsets of transitional $B$ cells as CD19+CD24+CD38+ (CD19, CD24, CD38 positive), unswitched memory B cells as CD19+IgD+CD27+ (CD19, immunoglobulin D positive, CD19 positive), switched memory B as CD19+IgD-CD27+ (CD19 positive, immunoglobulin $\mathrm{D}$ negative, $\mathrm{CD} 27$ positive), plasmablasts as CD19lowCD20-CD27+CD38 high, and plasma cells as CD19-CD20-CD27high CD38high CD138+.

\section{Statistical analyses}

We performed statistical analyses using SPSS version 15.0 (SPSS Inc, Chicago, IL, USA). According to the Kolmogorov-Smirnov test, all continuous variables did not show normal distribution. Therefore, nonparametric tests were used for all continuous variables. Continuous variables are shown as medians and interquartile ranges (IQR), whereas qualitative variables are shown as total number of observations and percentages.

\section{Results}

Main patient characteristics are shown in Table 1. Median rATG dose was $6.6 \mathrm{mg} / \mathrm{kg}$ (IQR, 5.1-8.0 $\mathrm{mg} / \mathrm{kg}$ ). Lymphocyte subpopulation changes are reported in Table 2 (no rATG group) and Table 3 (rATG group) and in Figures 1 and 2. Total lymphocytes, CD3 cells, and CD4 cells were significantly decreased at 6 
and 12 months only in the group of patients who received rATG. In contrast, the CD19 population did not change at 6 and 12 months after rATG induction. Of note, 1-year circulating plasma cells remained significantly lower than pretransplant levels only in patients who received rATG. Other B-cell subpopulations (naïve, unswitched/switched memory B cells, mature) did not change significantly after rATG induction therapy.

\begin{tabular}{|c|c|c|c|}
\hline & $\begin{array}{l}\text { No rATG } \\
(\mathrm{n}=15)\end{array}$ & $\begin{array}{c}\text { rATG } \\
(n=20)\end{array}$ & $\begin{array}{c}\text { PValue } \\
\text { (Mann-Whitney) }\end{array}$ \\
\hline Recipient age, y & $53(44-65)$ & $52(41-60)$ & .499 \\
\hline Male recipient & $60 \%$ & $60 \%$ & 1.000 \\
\hline SPK & $0 \%$ & $15 \%$ & .117 \\
\hline Hypersensitized & $0 \%$ & $25 \%$ & .036 \\
\hline Donor age, y & $53(48-59)$ & $51(38-64)$ & .681 \\
\hline DCD & $0 \%$ & $55 \%$ & .001 \\
\hline$c P R A>20 \%$ & $0 \%$ & $25 \%$ & .036 \\
\hline Mismatches, No. & $4(4-5)$ & $5(3-5)$ & .882 \\
\hline Retransplant & $13.3 \%$ & $25.0 \%$ & .393 \\
\hline Cold ischemia time, min & $19(17-21)$ & $12(8-19)$ & .074 \\
\hline DGF & $33.3 \%$ & $30.0 \%$ & .833 \\
\hline $\begin{array}{l}\text { 1-year creatinine, } \\
\text { mg/dL }\end{array}$ & $1.37(1.00-1.95)$ & $1.37(1.04-1.91)$ & .934 \\
\hline $\begin{array}{l}\text { 1-year eGFR, } \\
\mathrm{mL} / \mathrm{min} / 1.73 \mathrm{~m}^{2}\end{array}$ & $69.4(38.9-75.8)$ & $56.5(40.5-81.6)$ & .856 \\
\hline $\begin{array}{l}\text { 1-year proteinuria, } \\
\text { mg/day }\end{array}$ & $270(206-945)$ & $384(221-846)$ & .784 \\
\hline 1-year acute rejection & $20.0 \%$ & $25.0 \%$ & .727 \\
\hline 1-year tacrolimus & $100 \%$ & $95 \%$ & .380 \\
\hline 1-year mycophenolate & $93.3 \%$ & $95.0 \%$ & .833 \\
\hline 1-year mTOR inhibitor & $0 \%$ & $5 \%$ & .380 \\
\hline 1-year prednisone & $86.7 \%$ & $80.0 \%$ & .605 \\
\hline
\end{tabular}

Abbreviations: cPRA, calculated panel reactive antibody; DCD, donation after cardiac death; DGF, delayed graft function; eGFR, estimated glomerular filtration rate; mTOR, mammalian target of rapamycin; rATG, rabbit antithymocyte globulin; SPK, simultaneous pancreas-kidney transplant Data are shown as frequency (qualitative variables) or median and interquartile range (quantitative variables).

Table 2. Evolution of Peripheral Blood Lymphocyte Subpopulation in Patients Not Receiving Induction With Rabbit Antithymocyte Globulin $(\mathrm{n}=15)$

\begin{tabular}{|lccc|}
\hline Subpopulation & \multicolumn{3}{c|}{ Median (Interquartile Range) } \\
& Pretransplant & 6 Months & 12 Months \\
Total & & & \\
$\quad$ Iymphocytes & $1515(1182-1953)$ & $1724(1243-1994)$ & $1630(1360-2294)$ \\
CD3 & $1116(920-1648)$ & $1435(910-1632)$ & $1254(1014-1975)$ \\
CD4 & $800(549-1008)$ & $756(453-953)$ & $757(608-892)$ \\
CD19 & $90(63-229)$ & $91(41-165)$ & $92(69-163)$ \\
Naïve & $8(2-33)$ & $5(1-22)$ & $13(7-30)$ \\
Unswitched & & & \\
$\quad$ memory B & $6(4-11)$ & $6(4-15)$ & $7(5-9)$ \\
Switched & & & $18(9-41)$ \\
$\quad$ memory B & $15(6-26)$ & $12(5-19)$ & $4(2-12)$ \\
Mature B & $6(1-14)$ & $2(1-4) a$ & $25(12-35)$ \\
Plasma cells & $39(6-50)$ & $24(10-35)$ & \\
\hline
\end{tabular}

${ }^{\mathrm{a}} P=.030$ for pretransplant vs 6 months (Wilcoxon test).

We observed significant differences in plasma cell numbers at 12 months after transplant between patients who received rATG and patients who did not receive it (median and IQR of 5 [3-17] vs 25 [12-35]; $P=.001)$. In contrast, we observed no significant differences in plasma cells pretransplant (median and IQR of 22 [12-84] vs 39 [6-50]; $P=.461$ ) or at 6 months (median and IQR of 21 [8-30] vs 24 [1035]; $P=.433$ ) between both groups of patients.

Table 3. Evolution of Peripheral Blood Lymphocyte Subpopulation in Patients Receiving Induction With Rabbit Antithymocyte Globulin ( $\mathrm{n}=20)$

\begin{tabular}{|lccc|}
\hline Subpopulation & \multicolumn{3}{c|}{ Median (Interquartile Range) } \\
& Pretransplant & 6 Months & 12 Months \\
Total & & & \\
$\quad$ lymphocytes & $1626(898-2063)$ & $681(555-1294)^{\mathrm{a}}$ & $943(530-1457)^{\mathrm{c}}$ \\
CD3 & $1322(707-1627)$ & $524(412-959)^{\mathrm{a}}$ & $617(343-984)^{\mathrm{b}}$ \\
CD4 & $717(446-931)$ & $161(95-270)^{\mathrm{a}}$ & $180(130-306)^{\mathrm{b}, \mathrm{c}}$ \\
CD19 & $97(51-192)$ & $42(33-185)$ & $87(53-152)$ \\
Naïve & $12(5-19)$ & $7(2-23)$ & $8(4-20)$ \\
Unswitched & & & \\
$\quad$ memory B & $5(3-28)$ & $5(2-16)$ & $10(2-22)$ \\
Switched & & & \\
$\quad$ memory B & $14(5-25)$ & $12(3-35)$ & $14(4-19)$ \\
Mature B & $3(2-7)$ & $2(0.4-8)$ & $5(3-12)$ \\
Plasma cells & $22(12-84)$ & $21(8-30)$ & $5(3-17)^{\mathrm{d}, \mathrm{e}}$ \\
\hline
\end{tabular}

${ }^{\mathrm{a}} P=.05$, pretransplant vs 6 months; ${ }^{\mathrm{b}} \mathrm{P}<.05$, pretransplant vs 12 months; ${ }^{\mathrm{c}} P<.05,6$ months vs 12 months; ${ }^{\mathrm{d}} P=.007$, pretransplant vs 12 months; ${ }^{\mathrm{e}} P=.015,6$ months vs 12 months (Wilcoxon test).

Figure 1. Changes in Lymphocyte Subpopulation (Total Lymphocytes and CD3, CD4, and CD19 Cells) in Peripheral Blood From Patients Treated and Not Treated With Rabbit Antithymocyte Globulin
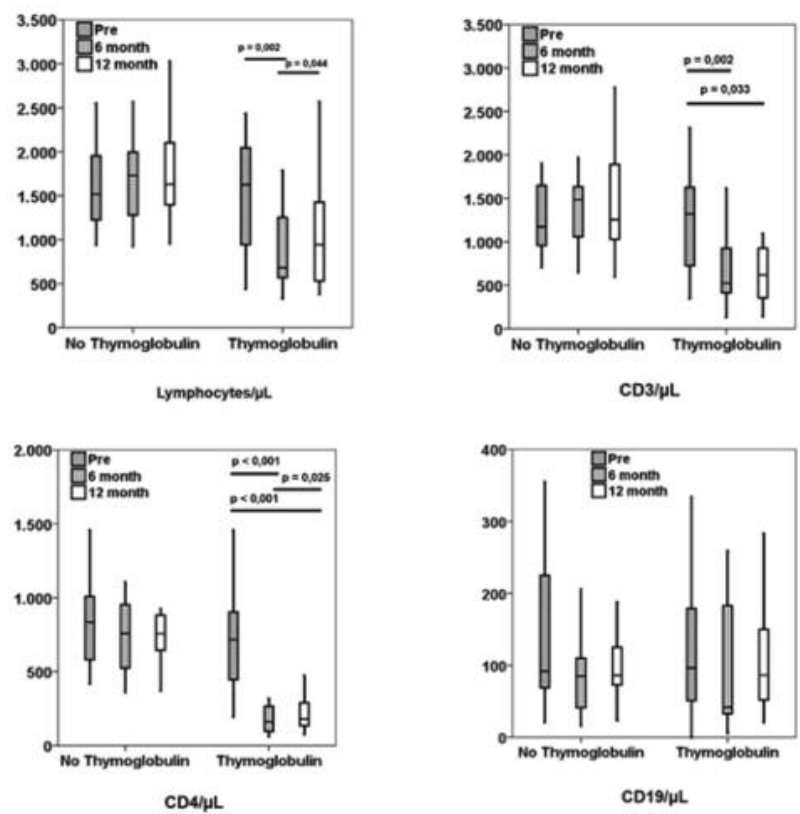

Variables related to 1-year levels of peripheral blood plasma cells in patients treated with rATG were the number of circulating CD4 cells at 12 months $(\mathrm{r}=0.522, P=.022)$, the number of circulating CD19 cells $(r=0.691, P=.001)$, and eGFR at 12 months $(\mathrm{r}=0.648, P=.003)$. However, recipient age 
$(P=.393), \operatorname{sex}(P=.196)$, steroid use $(P=.885)$, calculated panel reactive antibody $>20 \%(P=.262)$, donation after cardiac death $(P=.968)$, and acute rejection $(P=.219)$ were not significantly associated with peripheral blood plasma cell level. After linear regression analysis, CD19 $(0.076,95 \%$ confidence interval [95\% CI], 0.026-0.127; $P=.006)$ and eGFR (0.167, 95\% CI, 0.039-0.295; $P=.014)$ remained independently related to peripheral blood plasma cell level at 12 months.

Variables related to levels of 1-year circulating plasma cells in patients not treated with rATG were the number of circulating CD4 and CD19 cells at 12 months $(\mathrm{r}=0.763, P=.001$ and $\mathrm{r}=0.597, P=.024$, respectively). However, eGFR at 12 months $(P=.751)$, recipient age $(P=.082)$, sex $(P=.898)$, steroid use $(P=.549)$, and acute rejection $(P=.555)$ were not related.

Figure 2. Changes in Number of Peripheral Blood Plasma Cells in Patients Treated and Not Treated With Rabbit Antithymocyte Globulin

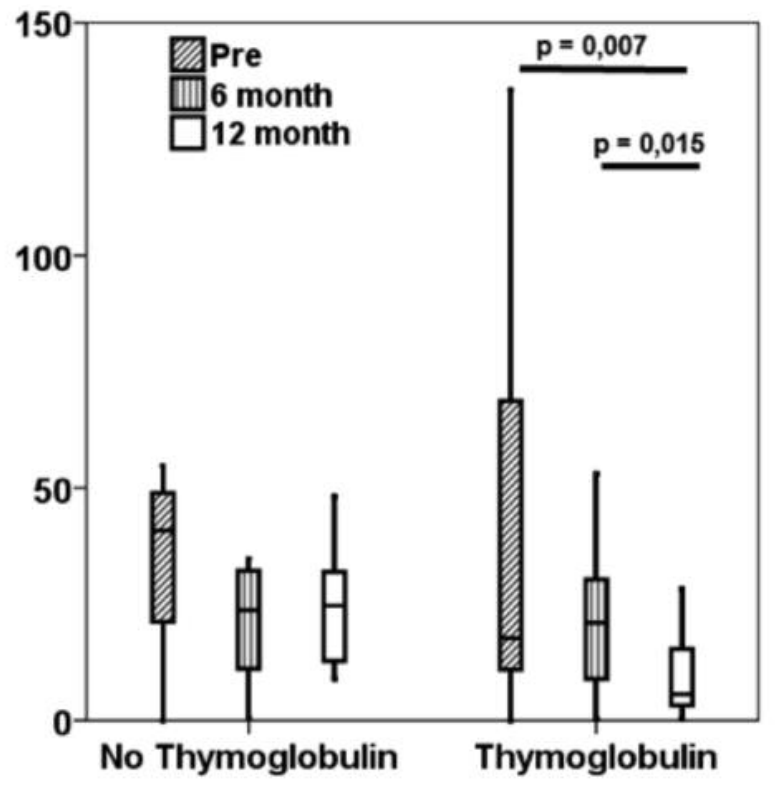

Plasma cell/ $/ \mathrm{L}$

\section{Discussion}

Although it is well known that rATG exerts its main immunosuppressive effects by depleting $\mathrm{T}$ cells, some of these effects are driven through B-cell depletion and down-regulation of cell surface expression of some leukocyte adhesion molecules (previously reviewed ${ }^{28,29}$ ). The influence on the
B-cell population is due to the presence of $B$ cells and some B-cell surface antigens in the thymic preparation used for $\mathrm{rATG}$ production. In this sense, Zand and associates reported that CD20-positive B cells could be found in the pediatric thymus. ${ }^{30}$ Consequently, rATG preparations have different antibodies against B-cell populations that can promote apoptosis in these cells in vitro at clinically relevant concentrations. ${ }^{30-33}$ The influence of rATG on $\mathrm{B}$ cells has been demonstrated in animal models. Préville and associates reported that rATG treatment induced a partial B-cell depletion in a cynomolgus monkey model. ${ }^{34}$ However, this effect has not been consistently shown in in vivo studies performed in humans. Although some authors detected some depletion of B cells or B-cell subsets in humans, mainly in the initial months, ${ }^{35-37}$ we and others found no significant changes in B-cell lymphocytes or in B-cell subsets. ${ }^{38,39}$ Differences in transplant patient characteristics, rATG dose, sample timing, and batchto-batch variations in the quantity of B-cell antigens in the thymic preparation can partly explain these differences. ${ }^{30,35-39}$

Similar findings would be expected regarding plasma cells. Plasma cell antigens, mainly CD138, are found in pediatric thymic parenchyma, and plasma cell apoptosis induced by rATG has been reported in in vitro studies by some but not all authors. ${ }^{30,33,40,41}$ Considering this potential role of rATG, we could have found an early effect of rATG that reduced the number of circulating plasma cells, but we detected no significant change in the number of peripheral blood plasma cells at month 6 . In contrast, the main finding of our study was that rATG induced a late depletion on circulating plasma cells that was only detected at month 12. No previous studies have analyzed the long-term effects of rATG on B-cell subsets including plasma cells. Potential mechanisms that explain this finding are not known. On the one hand, regarding T cells, rATG exerts a late effect that influences the different T-cell subsets beyond the period in which rATG can be detected in blood. ${ }^{42}$ Although not explored, a similar mechanism could be possible for plasma cells. On the other hand, rATG modifies the reconstitution of T-cell subpopulations (as reviewed previously28,29,35); among them, Tfollicular helper cells have a strong influence on the development and maintenance of human circulating antigen-induced plasma cells. ${ }^{43,44}$ Hence, T-follicular helper cell depletion and T-cell subset changes 
promoted by rATG could favor a late (12 month) reduction in circulating plasma cells, whereas longlived plasma cells were not affected earlier (that is, at 6 months). Although this mechanism was not explored in our study, the positive correlation between CD4-positive cells and plasma cells that we found could support this hypothesis.

Kidney transplant induction with rATG contributes to the reduction of acute rejection in the short and long term compared with placebo or no treatment and with interleukin 2 receptor monoclonal antibodies in high-risk patients. ${ }^{4,5,45-48}$ Because of this, current guidelines suggest using a lymphocyte-depleting agent for kidney transplant recipients at high immunologic risk. ${ }^{1,2}$ This beneficial effect of rATG is mainly explained by its potent effect on the T-cell compartment, but a potential role in B-cell subpopulations cannot be discarded; for example, rATG has been used to treat and prevent AbMR. ${ }^{21,49}$ Because rATG is preferentially used in patients with high immunologic risk and the yearly rate of donor-specific antibody appearance is low, until recently, it has been difficult to demonstrate that rATG helps to reduce the development of donor-specific antibodies. Brokhof and colleagues reported that rATG induction is associated with a lower incidence of de novo donor-specific antibodies in moderately sensitized renal transplant recipients. ${ }^{18}$ Because bone marrow plasma cells are the origin of donor-specific antibodies and circulating plasma cells reflect this population, our finding of lower peripheral blood plasma cells in patients who received rATG could explain how it contributes to controlling donor-specific antibody appearance.

As previously reported, $r$ ATG is a key component of several immunosuppressive regimens designed to induce tolerance in kidney transplant recipients. ${ }^{25-27}$ In these therapeutic protocols, rATG is mainly used because it has potent unspecific immunosuppressive effects. However, rATG may also promote some tolerogenic mechanisms. For example, treatment with rATG induced a significant proliferation of regulatory $\mathrm{T}$ cells. ${ }^{50,51}$ Because certain B-cell subpopulations relate to a "tolerant" state, we analyzed changes in B-cell subsets after rATG induction. Although we did not find an increase in the number of näive B cells, the low number of plasma cells that we found has also been previously related to a tolerant situation with stable kidney graft function in the absence of immunosuppression. ${ }^{16}$ In contrast, patients who were treated with alemtuzumab as induction therapy showed a "tolerant" B signature with higher rate of näive and transitional B cells at month 6 , but this was not shown in plasma cells. ${ }^{52}$ Although kidney transplant outcomes are similar with both induction drugs, they have different longterm effects on B-cell subpopulations. ${ }^{53}$

Our study has several limitations. First, like in similar single-center studies, $, 38,39,52$ the number of patients included was low. Second, patients received rATG due to different indications, mainly because of high risk for delayed graft function. Interestingly, the results did not change after exclusion of hypersensitized patients whose plasma cells were not significantly different at any moment. Last, it would have been interesting to draw intermediate blood samples between the transplant procedure and month 6 to know the initial changes of B-cell subsets due to rATG. Budget constraints required limiting the number of samples and patients analyzed. Conversely, the strengths of our study are its prospective nature, the complete follow-up of all patients up to month 12 , and the significant number of B-cell subpopulations studied.

To conclude, we analyzed the effects of rATG induction on B-cell subpopulations, including plasma cells, in vivo in humans for the first time. We disclosed a not previously reported late reduction of plasma cells induced by rATG. This effect can contribute to diminishing the development of donorspecific antibodies and further AbMR and graft loss, which could also promote tolerance. Although the underlying mechanisms are not known, T-cell (specifically CD4-positive) depletion may interfere in the T-B cell cooperation necessary for long-lived plasma cell formation.

\section{References}

1. Kidney Disease: Improving Global Outcomes Transplant Work G. KDIGO clinical practice guideline for the care of kidney transplant recipients. Am J Transplant. 2009;9 Suppl 3:S1-S155.

2. Heemann U, Abramowicz D, Spasovski G, Vanholder R, European Renal Best Practice Work Group on Kidney T. Endorsement of the Kidney Disease Improving Global Outcomes (KDIGO) guidelines on kidney transplantation: a European Renal Best Practice (ERBP) position statement. Nephrol Dial Transplant. 2011;26(7): 2099-2106.

3. Opelz G, Unterrainer C, Susal C, Dohler B. Efficacy and safety of antibody induction therapy in the current era of kidney transplantation. Nephrol Dial Transplant. 2016;31(10):1730-1738.

4. Hill P, Cross NB, Barnett AN, Palmer SC, Webster AC. Polyclonal and monoclonal antibodies for induction therapy in kidney transplant recipients. Cochrane Database Syst Rev. 2017;1:CD004759.

5. Webster AC, Ruster LP, McGee R, et al. Interleukin 2 receptor antagonists for kidney transplant recipients. Cochrane Database Syst Rev. 2010(1):CD003897. 
6. ANZDATA Registry Web site. 39th Report CTAaNZDaTR, Adelaide, Australia; 2017. http://www.anzdata.org.au. Accessed July 9, 2017.

7. OPTN/SRTR 2015 Annual Data Report: Introduction. Am J Transplant. 2017;17 Suppl 1:11-20.

8. Rodrigo E, Fernandez-Fresnedo G, Robledo C, et al. Heterogeneity of induction therapy in Spain: changing patterns according to year, centre, indications and results. NDT Plus. 2010;3(Suppl_2):ii9-ii14.

9. Hardinger $\mathrm{KL}$, Brennan DC, Klein CL. Selection of induction therapy in kidney transplantation. Transpl Int. 2013;26(7):662-672.

10. Thiyagarajan UM, Ponnuswamy A, Bagul A. Thymoglobulin and its use in renal transplantation: a review. Am J Nephrol. 2013; 37(6):586-601.

11. Sellares J, de Freitas DG, Mengel $M$, et al. Understanding the causes of kidney transplant failure: the dominant role of antibodymediated rejection and nonadherence. Am J Transplant. 2012;12(2):388-399.

12. Wiebe C, Gibson IW, Blydt-Hansen TD, et al. Evolution and clinical pathologic correlations of de novo donor-specific HLA antibody post kidney transplant. Am J Transplant. 2012;12(5):1157-1167.

13. Newell KA, Asare A, Kirk AD, et al. Identification of a B cell signature associated with renal transplant tolerance in humans. J Clin Invest. 2010;120(6):1836-1847.

14. Newell KA, Asare A, Sanz I, et al. Longitudinal studies of a B cellderived signature of tolerance in renal transplant recipients. Am J Transplant. 2015;15(11):2908-2920.

15. Sagoo P, Perucha E, Sawitzki B, et al. Development of a crossplatform biomarker signature to detect renal transplant tolerance in humans. J Clin Invest. 2010;120(6):1848-1861.

16. Chesneau M, Pallier A, Braza F, et al. Unique B cell differentiation profile in tolerant kidney transplant patients. Am J Transplant. 2014;14(1):144-155.

17. Shabir S, Girdlestone J, Briggs D, et al. Transitional B lymphocytes are associated with protection from kidney allograft rejection: a prospective study. Am J Transplant. 2015;15(5):1384-1391.

18. Brokhof MM, Sollinger HW, Hager DR, et al. Antithymocyte globulin is associated with a lower incidence of de novo donorspecific antibodies in moderately sensitized renal transplant recipients. Transplantation. 2014:97(6):612-617.

19. Kanter Berga J, Pallardo Mateu LM, Beltran Catalan S, et al. Donorspecific HLA antibodies: risk factors and outcomes after kidney transplantation. Transplant Proc. 2011;43(6):2154-2156.

20. Rafiei M, Kittleson M, Patel J, et al. Anti-thymocyte gammaglobulin may prevent antibody production after heart transplantation. Transplant Proc. 2014;46(10):3570-3574.

21. Bachler K, Amico P, Honger G, et al. Efficacy of induction therapy with ATG and intravenous immunoglobulins in patients with lowlevel donor-specific HLA-antibodies. Am J Transplant. 2010;10(5): 1254-1262.

22. Maki T, Gottschalk R, Wood ML, Monaco AP. Specific unresponsiveness to skin allografts in anti-lymphocyte serumtreated, marrow-injected mice: participation of donor marrowderived suppressor T cells. J Immunol. 1981;127(4):1433-1438.

23. Hale DA, Gottschalk R, Umemura A, Maki $T$, Monaco AP. Immunologic mechanisms in tolerance produced in mice with nonradiation-based lymphoablation and donor-specific bone marrow. Transplantation. 2002;74(4):477-484.

24. Hale DA, Gottschalk R, Umemura A, Maki $T$, Monaco AP. Establishment of stable multilineage hematopoietic chimerism and donor-specific tolerance without irradiation. Transplantation. 2000;69(7):1242-1251

25. Kawai T, Sachs DH, Sprangers B, et al. Long-term results in recipients of combined HLA-mismatched kidney and bone marrow transplantation without maintenance immunosuppression. Am J Transplant. 2014;14(7):1599-1611.

26. Scandling JD, Busque S, Dejbakhsh-Jones S, et al. Tolerance and withdrawal of immunosuppressive drugs in patients given kidney and hematopoietic cell transplants. Am J Transplant. 2012;12(5): 1133-1145.

27. Vanikar AV, Trivedi HL, Thakkar UG. Six years' experience of tolerance induction in renal transplantation using stem cell therapy. Clin Immunol. 2018;187:10-14.
28. Bamoulid J, Crepin T, Courivaud C, et al. Antithymocyte globulins in renal transplantation-from lymphocyte depletion to lymphocyte activation: The doubled-edged sword. Transplant Rev (Orlando). 2017;31(3):180-187.

29. Pascual J, Zuckermann A, Djamali A, Hertig A, Naesens M. Rabbit antithymocyte globulin and donor-specific antibodies in kidney transplantation--A review. Transplant Rev (Orlando). 2016;30(2):8591.

30. Zand MS, Vo T, Huggins J, et al. Polyclonal rabbit antithymocyte globulin triggers B-cell and plasma cell apoptosis by multiple pathways. Transplantation. 2005;79(11):1507-1515.

31. Thaunat O, Koenig A, Leibler C, Grimbert P. Effect of immunosuppressive drugs on humoral allosensitization after kidney transplant. J Am Soc Nephrol. 2016;27(7):1890-1900.

32. Clatworthy MR. Targeting B cells and antibody in transplantation. Am J Transplant. 2011;11(7):1359-1367.

33. Mohty M. Mechanisms of action of antithymocyte globulin:T-cell depletion and beyond. Leukemia. 2007;21(7):1387-1394.

34. Preville $X$, Flacher $M$, LeMauff $B$, et al. Mechanisms involved in antithymocyte globulin immunosuppressive activity in a nonhuman primate model. Transplantation. 2001:71(3):460-468.

35. Gurkan S, Luan Y, Dhillon N, et al. Immune reconstitution following rabbit antithymocyte globulin. Am J Transplant. 2010;10(9):21322141.

36. Sageshima J, Ciancio G, Guerra G, et al. Prolonged lymphocyte depletion by single-dose rabbit anti-thymocyte globulin and alemtuzumab in kidney transplantation. Transpl Immunol. 2011;25(2-3):104-111.

37. Vacher-Coponat $H$, Brunet C, Moal V, et al. Tacrolimus/mycophenolate mofetil improved natural killer lymphocyte reconstitution one year after kidney transplant by reference to cyclosporine/azathioprine. Transplantation. 2006; 82(4):558-566.

38. Morelon $\mathrm{E}$, Lefrancois $\mathrm{N}$, Besson $\mathrm{C}$, et al. Preferential increase in memory and regulatory subsets during T-lymphocyte immune reconstitution after Thymoglobulin induction therapy with maintenance sirolimus vs cyclosporine. Transpl Immunol. 2010; 23(1-2):53-58

39. Kho MM, Bouvy AP, Cadogan M, et al. The effect of low and ultralow dosages Thymoglobulin on peripheral T, B and NK cells in kidney transplant recipients. Transpl Immunol. 2012;26(4) 186-190.

40. Perry DK, Burns JM, Pollinger HS, et al. Proteasome inhibition causes apoptosis of normal human plasma cells preventing alloantibody production. Am J Transplant. 2009:9(1):201-209.

41. Ramos EJ, Pollinger HS, Stegall MD, et al. The effect of desensitization protocols on human splenic B-cell populations in vivo. Am J Transplant. 2007;7(2):402-407.

42. Waller EK, Langston AA, Lonial S, et al. Pharmacokinetics and pharmacodynamics of anti-thymocyte globulin in recipients of partially HLA-matched blood hematopoietic progenitor cell transplantation. Biol Blood Marrow Transplant. 2003;9(7): 460-471.

43. Ramos-Amaya A, Rodriguez-Bayona B, Lopez-Blanco R, et al. Survival of human circulating antigen-induced plasma cells is supported by plasma cell-niche cytokines and T follicular helper lymphocytes. J Immunol. 2015;194(3):1031-1038.

44. Nutt SL, Hodgkin PD, Tarlinton DM, Corcoran LM. The generation of antibody-secreting plasma cells. Nat Rev Immunol. 2015;15(3): 160-171.

45. Lentine KL, Schnitzler MA, Xiao H, Brennan DC. Long-term safety and efficacy of antithymocyte globulin induction: use of integrated national registry data to achieve ten-year follow-up of 10-10 Study participants. Trials. 2015;16:365.

46. Hellemans R, Hazzan M, Durand D, et al. Daclizumab versus rabbit antithymocyte globulin in high-risk renal transplants: five-year follow-up of a randomized study. Am J Transplant. 2015;15(7): 1923-1932.

47. Brennan DC, Daller JA, Lake KD, et al. Rabbit antithymocyte globulin versus basiliximab in renal transplantation. N Engl J Med. 2006;355(19):1967-1977. 
48. Willoughby LM, Schnitzler MA, Brennan DC, et al. Early outcomes of thymoglobulin and basiliximab induction in kidney transplantation: application of statistical approaches to reduce bias in observational comparisons. Transplantation. 2009;87(10): 1520-1529.

49. Shah A, Nadasdy T, Arend L, et al. Treatment of C4d-positive acute humoral rejection with plasmapheresis and rabbit polyclonal antithymocyte globulin. Transplantation. 2004;77(9):1399-1405.

50. Valdez-Ortiz R, Bestard O, Llaudo I, et al. Induction of suppressive allogeneic regulatory $T$ cells via rabbit antithymocyte polyclonal globulin during homeostatic proliferation in rat kidney transplantation. Transpl Int. 2015;28(1):108-119.

51. Shimony O, Nagler A, Gellman YN, et al. Anti-T lymphocyte globulin (ATG) induces generation of regulatory T cells, at least part of them express activated CD44. J Clin Immunol. 2012;32(1):173-188.
52. Heidt S, Hester J, Shankar S, Friend PJ, Wood KJ. B cell repopulation after alemtuzumab induction-transient increase in transitional $\mathrm{B}$ cells and long-term dominance of naive B cells. Am J Transplant. 2012;12(7):1784-1792.

53. Sampaio MS, Chopra B, Sureshkumar KK. Depleting antibody induction and kidney transplant outcomes: a paired kidney analysis. Transplantation. 2017;101(10):2527-2535. 